\title{
Deformation monitoring and analysis of a long-span cable-stayed bridge during strong typhoons
}

\author{
Jianxiao Mao ${ }^{1}$, Hao Wang ${ }^{1 *}$, Yichao $\mathrm{Xu}^{1,2}$ and Hang Li ${ }^{3}$
}

\author{
* Correspondence: wanghao1980@ \\ seu.edu.cn \\ ${ }^{1}$ Key Laboratory of C\&PC Structures \\ of Ministry of Education, Southeast \\ University, Nanjing 201189, China \\ Full list of author information is \\ available at the end of the article
}

\begin{abstract}
Deformation monitoring of the girders and towers during strong winds or typhoons is vitally important for serviceability and safety assessment of in-service long-span bridges. Although some field measurements were carried out, our understanding on the features of the bridge deformation during high-speed winds is still limited; therefore, more monitoring-based studies are still required. In this study, the displacements of a long-span cable-stayed bridge during three typhoons are recorded by the Global Positioning System (GPS) in its Structural Health Monitoring (SHM) system. The monitored displacements are decomposed into static and dynamic components using the autoregressive moving average model. The outliers and the low-frequency colored noise in the dynamic components are then analyzed and eliminated. On that basis, the relationship between the static displacements and environmental factors, in terms of wind and temperature, is investigated. Afterwards, the variation of dynamic displacements of the bridge is analyzed with respect to the surrounding environments. Results show that the structural temperature is the major reason that changes the static deformation of the bridge. The dynamic deformation of the girder is mainly controlled by the in-situ wind speed. Nevertheless, the influence of structural temperature on dynamic deformation is mildly. Conclusions are aimed to provide a reference for wind resistant design and assessment of similar long-span bridges.
\end{abstract}

Keywords: Long-span bridge, Deformation, Typhoon, Temperature, Structural health monitoring (SHM)

\section{Introduction}

Large quantities of long-span bridges have been built around the world over the last decades. These long-span bridges are featured as flexible and are sensitive to wind loads; the wind excitations may cause aggressive structural vibration (Zhu and Zhang 2016). Large vibration responses may lead to traffic accidents on the bridge deck (Zhu et al. 2012), failure of accessory components(Zhang et al. 2014), progressive structural damage (Fujino and Yoshida 2002), and structural collapse (Billah and Scanlan 1991). With the increase of global climatic change, weather disasters (e.g. typhoons, tornadoes, and downburst) will take place with a high frequency, threatening the safety and

(c) The Author(s). 2020 Open Access This article is licensed under a Creative Commons Attribution 4.0 International License, which permits use, sharing, adaptation, distribution and reproduction in any medium or format, as long as you give appropriate credit to the original author(s) and the source, provide a link to the Creative Commons licence, and indicate if changes were made. The images or other third party material in this article are included in the article's Creative Commons licence, unless indicated otherwise in a credit line to the material. If material is not included in the article's Creative Commons licence and your intended use is not permitted by statutory regulation or exceeds the permitted use, you will need to obtain permission directly from the copyright holder. To view a copy of this licence, visit http://creativecommons.org/licenses/by/4.0/. 
serviceability of long-span bridges (Hao and Wu 2018; Huang and Chen 2009). Therefore, to obtain the timely information about in-service condition, long-span bridges are usually equipped with comprehensive structural health monitoring (SHM) systems (Fujino et al. 2016; Ko and Ni 2005; Mufti 2002; Ou and Li 2010; Spencer et al. 2004).

Displacement responses are indicators of loading conditions and can be utilized to assess structural performance; such that, displacement monitoring is essential for the SHM system of a long-span bridge (Yi et al. 2013b; Zhou and Sun 2019b). Different techniques are available for displacement monitoring including the total station, visionbased method, global positioning system (GPS), laser displacement sensor, accelerationbased integration methods, etc. The above-mentioned techniques can provide alternatives for displacement monitoring in their designed scenarios; however, the disadvantages summarized as follows could limit their usages for long-term field monitoring of long-span bridges. The total station, which can monitor static displacements, is usually applied only limited in bridge alignment monitoring during construction and in-service periods(Zhang et al. 2018). In addition, its monitoring precision would be affected by base-station movements and weather conditions. Vision-based method (Feng and Feng 2016), which can extract displacements from video images through template matching techniques, is able to provide rich information of structural deformation; however, the improvements of vision-based techniques are still required especially for long-term field monitoring. The laser doppler vibrometer can provide accurate monitoring results, however, is not suitable for long-term bridge monitoring since it is oftentimes placed on the ground underneath the bridge and cannot be left unattended(Nassif et al. 2005). The acceleration-based integration method (Gomez et al. 2018) estimates the displacement by integrating the acceleration twice; its accuracy cannot be guaranteed because of the low-frequency noise in the acceleration. GPS utilizes electric waves from satellites to monitor the threedimensional coordinate for obtaining the structural displacements (Jo et al. 2013). For example, Ashkenazi and Roberts (1997) installed a real-time kinematic GPS on UK's Humber bridge to record the real-time deflection data of the deck. The resolution of applied GPS system was $\pm 1 \mathrm{~mm}$ horizontally and $\pm 3 \mathrm{~mm}$ in height. They found that the measurement accuracy was influenced by the vibration $(1-2 \mathrm{~cm})$ of the pole which attached the antenna to the bridge. Xu and Chan (2009) demonstrated that GPS can accurately monitor windinduced dynamic displacements of long-span bridges, whose natural frequency was smaller than or equal to $1 \mathrm{~Hz}$, when the vibration amplitude was larger than its uncertainty level (5 $\mathrm{mm}$ in horizontal direction and $10 \mathrm{~mm}$ in vertical direction). In addition,, the sampling frequency of GPS technologies has been increased to $100 \mathrm{~Hz}$ (Yi et al. 2013a), however, its measurement accuracy for long-term dynamic displacement monitoring, particularly for the high-frequency vibration measurement, cannot be ensured. To sum up, GPS is one of the most popular techniques that has the potential to measure low frequency structural displacements, hence enabling it suitable for SHM of long-span bridges (Ashkenazi and Roberts 1997; Im et al. 2011; Wang et al. 2016b; Zhou and Sun 2019b).

The SHM systems have collected vast structural deformation data of long-span bridges as well as the surrounding environmental factors after years of operation. Such SHM data can improve our understanding about in-service structural deformation behaviors of long-span bridges. Based on the collected SHM data, series of studies on deformation of full-scale bridges have been carried out. Most of existing studies generally focus on temperature-induced structural deformation. For example, $\mathrm{Xu}$ et al. 
(2010) carried out a comprehensive study about temperature effect on a long suspension bridge based on its wind and SHM system; the statistical relationship between the effective temperature and displacement is then established. Zhou et al. (2018) proposed a closed-form approach for modeling thermal-induced deformation and validated the approach using one-year field monitoring data of a long-span arch bridge. Zhou and Sun (2019b) investigated mechanisms of thermally induced variations in girder length and mid-span deflection through plane geometric based on field measurements of an operational cable-stayed bridge. Besides, some studies were carried out to investigate the wind-induced displacements during strong winds or typhoons. Miyata et al. (2002) investigated full-scale measurement data on the Akashi-Kaikyo Bridge during two typhoons, and particularly focused on the variation property of static lateral deflection of the deck with wind speed. It was of great value to evaluate the static and dynamic behavior of such a large-scale long-span bridge during actual strong wind conditions. In addition, the monitored displacements were also applied to investigate the vortex-induced vibration for serviceability assessment (Hwang et al. 2019), and structural condition evaluation after ship collisions (Sun et al. 2017). To sum up, most of existing studies focused on recorded data during normal operational period; the relationship between the girder deformation and temperature was particularly investigated. Field monitoring studies focusing on disastrous scenarios, e.g., typhoons and earthquakes, are still limited, restricted our understanding of in-service performances of long-span bridges.

In this study, the SHM data of Sutong Cable-stayed Bridge (SCB), the longest cablestayed bridge in China, are utilized to investigate the varying deformations of the bridge during strong winds and typhoons. Three strong typhoons, i.e., Damrey, Haikui, and Bolaven, approached the southeast coast of China during August 2012. The SHM system of SCB recorded in-situ wind speeds, structural temperatures, and structural displacements during the whole process. The recorded data are utilized to analyze the variation of bridge deformations with respect to the structural temperatures and in-situ wind speed. The reached conclusions are aimed to providing references for safety and serviceability assessment of similar long-span cable-supported bridges during typhoons or strong winds.

\section{Engineering background and data source}

\subsection{SCB and its SHM system}

The SCB, with a main span of $1088 \mathrm{~m}$, is the longest cable-stayed bridge in China. To meet the designed spanning requirement, the streamline flat steel-box girder is applied to manufacture the main bridge deck. The bridge deck is supported by two reinforcedconcrete towers with inverted Y shape using 272 symmetrically distributed cables (Xing et al. 2014). Eight fluid viscous dampers equipped with restrainers are utilized as longitudinal supports at the junction of the deck and towers. To balance the self-weight of the main span, the iron bricks used as counterweights are installed at the two side spans. The corresponding mass at each side is $4327 \mathrm{t}$. The elevation and plan views of SCB are shown in Fig. 1. Three directions for the bridge, i.e., longitudinal, vertical, and transverse directions, are illustrated in Fig. 1.

A complete SHM system (Wang et al. 2016b) was equipped on SCB before it was open to traffic. Sensors such as anemometers, thermometers, GPSs, strain, accelerometers, etc., 


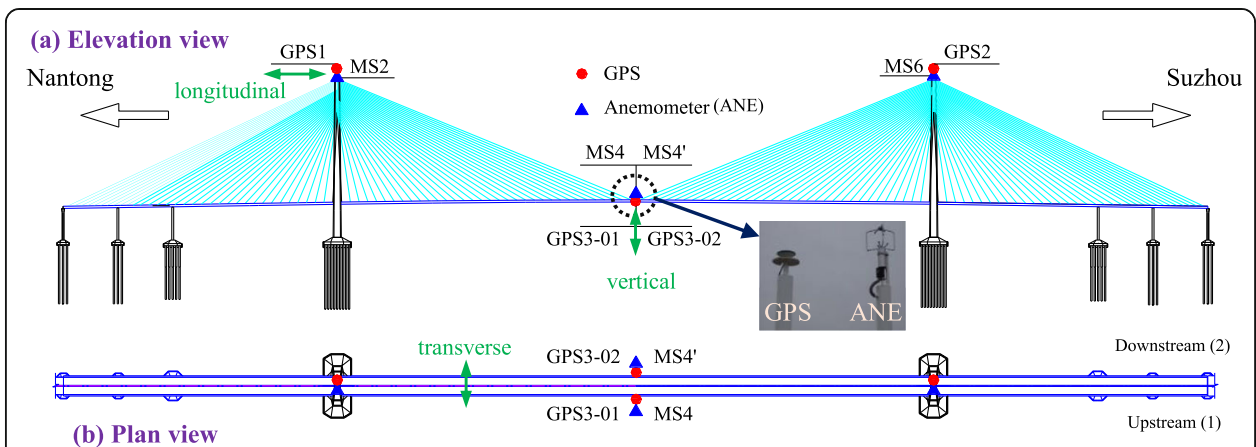

(b) Plan view

Fig. 1 Layout of anemometers and GPSs installed on SCB

are included for action and response monitoring. This study will focus on the structural displacements and their dependencies with environmental factors including wind and temperature; sensors including anemometers, thermometers, and GPSs will be introduced briefly. Figure 1 exhibits the layout of anemometers and GPSs installed on SCB.

As shown in Fig. 1, four ultrasonic anemometers are included in the SHM system to monitor the in-situ wind speed and direction. Two anemometers, i.e., MS4 and MS4', are respectively installed at upstream and downstream sides of the mid-span section of the main girder. The height and diameter of the steel pole for the anemometer are $4000 \mathrm{~mm}$ and $200 \mathrm{~mm}$, respectively. The other two anemometers, i.e., MS2 and MS6, are respectively installed at the top of north and south towers. The anemometers can measure the wind velocity up to $60 \mathrm{~m} / \mathrm{s}$ with a resolution of $0.01 \mathrm{~m} / \mathrm{s}$. The sampling frequency of the anemometers is $1 \mathrm{~Hz}$. For wind direction monitoring, the earth north is set as 0 degree and earth east is set as 90 degree. To minimize the shielding effects of the bridge and its affiliations on monitored wind, a steel pole is utilized to install the anemometer as shown in Fig. 2.

A GPS system with five stations, i.e., four monitoring stations and one base station, is embedded in the SHM system of SCB to monitor its real-time displacements. The GRX1200Pro system with the real-time kinematic is utilized. Two monitoring stations (GPS3-01 and GPS3-02) are installed at the mid-span section of the main girder, and the other two (GPS1 and GPS2) are respectively installed on the north and south towers. The height and diameter of the steel pole for GPS are $3200 \mathrm{~mm}$ and $200 \mathrm{~mm}$, respectively. The installed GPSs at the mid-span section are shown in Fig. 2. The sampling frequency of the GPS receiver is $1 \mathrm{~Hz}$. The measurement accuracy, given as root mean square, is $10 \mathrm{~mm}+1 \mathrm{ppm}$ according to the official manual instruction. In total, 27 thermometers are installed at the mid-span section of the main girder. Eight

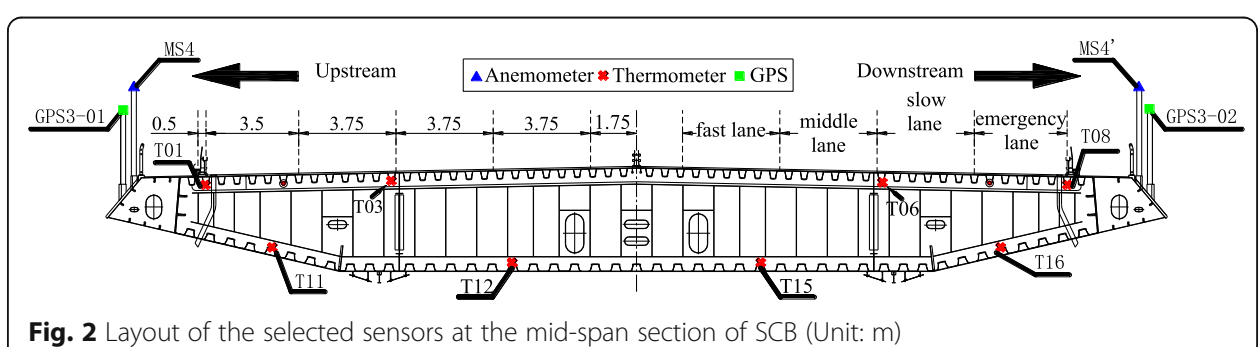

Fig. 2 Layout of the selected sensors at the mid-span section of SCB (Unit: m) 
thermometers (T01, T03, T06, T08, T11, T12, T15, and T16) are selected to monitor and analyze the structural thermal distribution. As shown in Fig. 2, the selected eight thermometers are uniformly distributed around the mid-span section of the main girder. The sampling frequency of thermometers are $10 \mathrm{~Hz}$.

\subsection{Monitored wind and temperature}

Three typhoons, namely, Damrey, Haikui, and Bolaven, went through the east coast of China and had great influences on SCB during that period. The moving paths of three typhoons are shown in Fig. 3.

As shown in Fig. 3, typhoon Damrey was generated at the northeast sea of Territory of Guam on July 27, 2012 and decreased to a tropical depression at Bohai sea on August 4, 2012. Typhoon Haikui was generated at the southeast sea of Iwo Jima on August 1, 2012 and downgraded to a tropical storm at Chizhou City on August 9, 2012. Typhoon Bolaven emerged at the southwest sea of Territory of Guam on August 17, 2012 and decreased to a tropical storm on August 29, 2012. According to the datasets provided by CMA (2012), the largest radius of tropical storm wind, i.e., the wind speed is larger than $17 \mathrm{~m} / \mathrm{s}$, during Haikui, Damrey, and Bolaven, are respectively 450 $\mathrm{km}, 200 \mathrm{~km}$, and $400 \mathrm{~km}$. At the same time, the closest distances between the typhoon eye and SCB were respectively $255 \mathrm{~km}$ (Damrey), $210 \mathrm{~km}$ (Haikui), and $360 \mathrm{~km}$ (Bolaven), respectively. Results indicate that SCB was located was located at spiral rain bands of the helical typhoon structures and could be greatly influenced by the wind loads. Because of the strong influence of typhoon Haikui, only small passenger vehicles with fewer than seven seaters are permitted to go through bridge with a limited speed smaller than $50 \mathrm{~km} / \mathrm{h}$ from 8:00 a.m. August 8 and 8:00 a.m. August 9. For the other

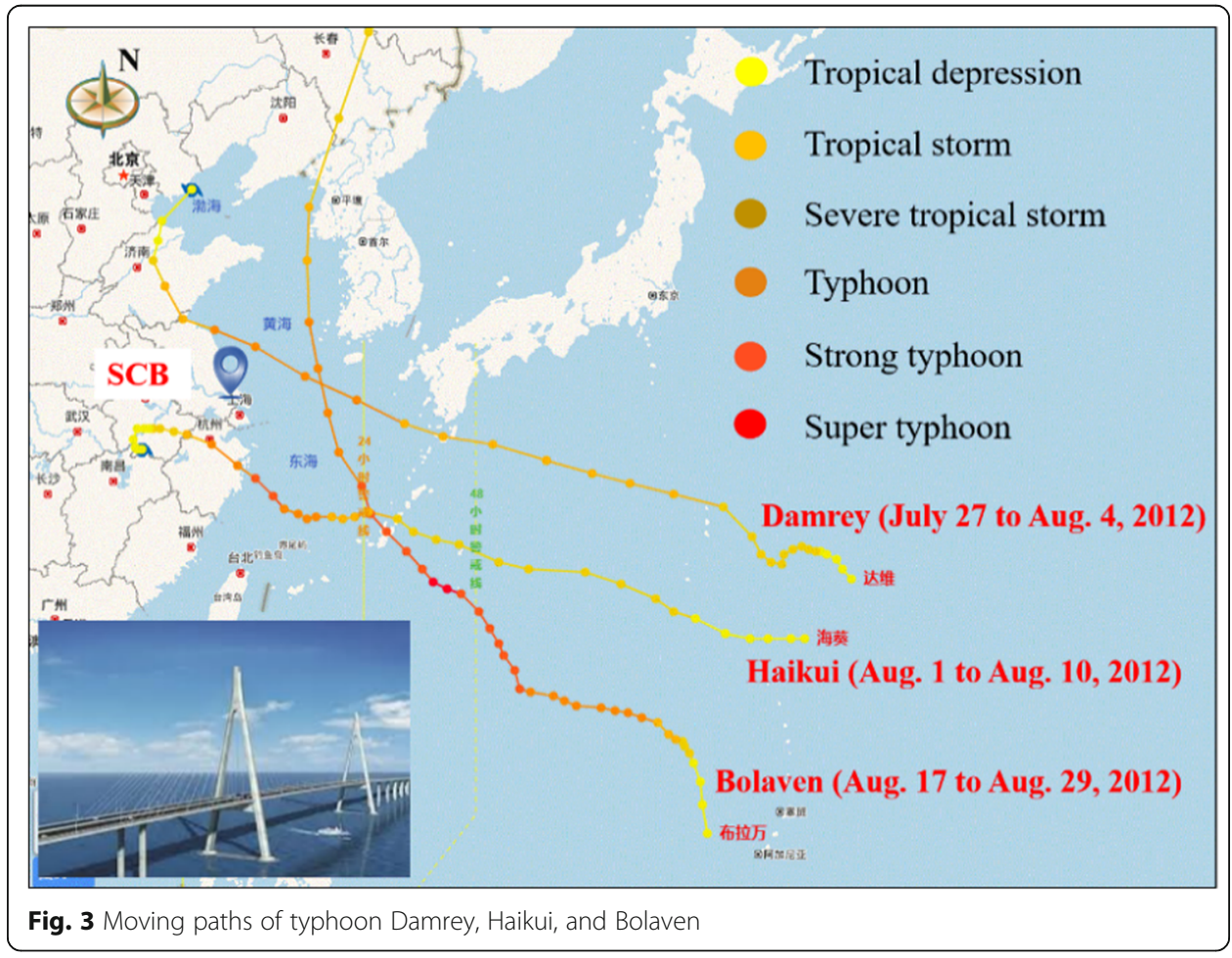


periods during these 30 days, SCB was opened to traffic as usual. The SHM system recorded in-situ wind speeds and direction, temperature, and structural responses, e.g. acceleration, strain, deformation, etc., during the whole process. The recorded 30-days data during August in 2012 will be applied for the following analysis.

The in-situ wind speed and direction of SCB from August 1 to 30 are recorded by its SHM sys. The measured wind speed is decomposed into the along-wind and the lateral-wind directions. Afterward, the average wind speed $\bar{U}$ in the along-wind direction over a determined time interval $T$, i.e., $10 \mathrm{~min}$, were calculated using the following wind speed model (Xu and Chen 2004),

$$
\begin{aligned}
& U(t)=\bar{U}+u(t) \\
& \bar{U}=\frac{1}{T} \int_{0}^{T} U(t) d t
\end{aligned}
$$

where $U(t)$ and $u(t)$ are the instantaneous along-wind speed and the corresponding turbulent wind speed at time instant $t$, respectively. Figure 4 exhibits the 10 -min average wind speed and direction measured by the four anemometers on the bridge. The solid and the dash lines represent the wind speed at different locations. The square and circle dots indicate the wind direction at different locations.

As shown in Fig. 4, the maximum 10-min average wind speed at the north tower (MS2) for the three typhoons are respectively $29.7 \mathrm{~m} / \mathrm{s}$ (Damrey), $46.1 \mathrm{~m} / \mathrm{s}$ (Haikui), $23.8 \mathrm{~m} / \mathrm{s}$ (Bolaven), indicating that SCB is within the influence scope of the above mentioned three typhoons. As shown in Fig. 4(a), the wind speed and direction at the two sides of the bridge girder are generally consistent with each other, but obvious

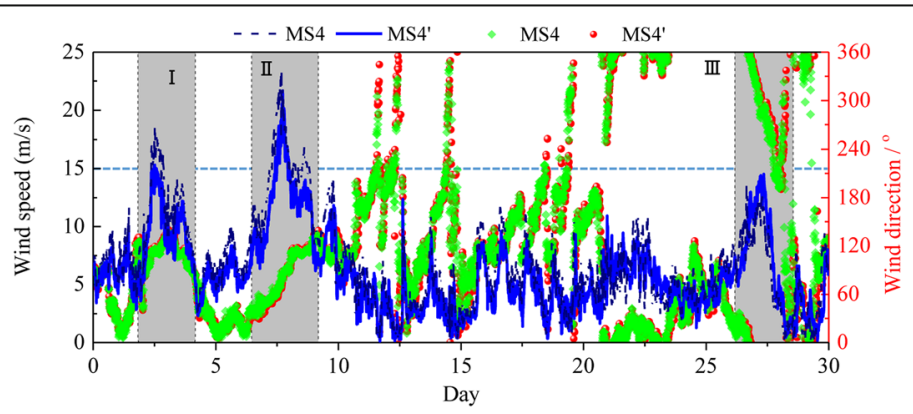

(a) Mid-span section

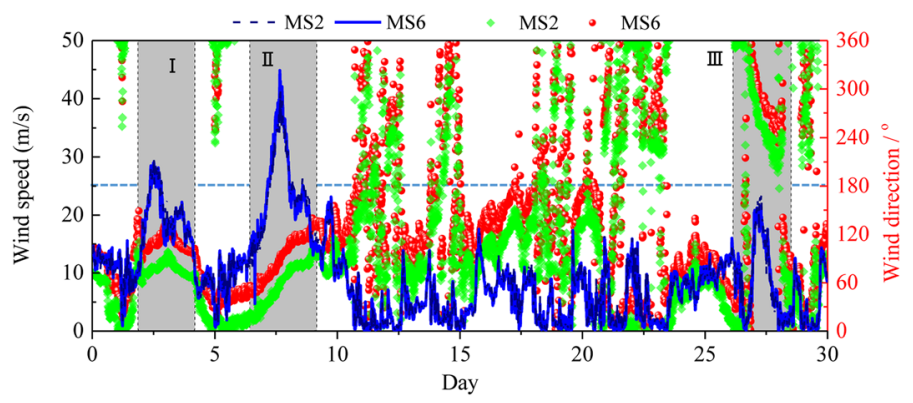

(b) Towers

Fig. 4 The 10-min average wind speed and direction 
differences can still be identified during typhoon periods. As shown in Fig. 4(b), the measured wind speeds at two towers are almost the same, while constant differences between their direction angles can be observed. To minimize the influence of the bridge and its affiliations on the anemometers, the wind speed and direction measured at the inflow side of the bridge will be utilized for the following analysis.

The selected eight thermometers shown in Fig. 2 are utilized to describe the thermal field of the mid-span section of SCB (Mao et al. 2019b). Figure 5 shows that the monitored temperatures of the mid-span section of the main girder during August 2012. The monitored temperatures in different channels are highly correlated with each other as shown in Fig. 6. Therefore, the average temperature in each 10 min will be utilized for the following analysis. One should also observe the temperature differences (almost $5{ }^{\circ} \mathrm{C}$ ) between T03 and T06 as they are both located at the top flange of the girder. The imbalance of traffic volumes at the two sides of the bridge could change the solar intensity and cause the corresponding thermal differences. In the morning and early afternoon, more vehicles are riding on the downstream side of the bridge, and the solar intensity on the road surface would be reduced. Therefore, the temperatures of T06 is a little larger than those of T03.

\subsection{Monitored bridge displacements}

The GPS stations monitor the real-time coordinates in north-south direction, east-west direction, and altitudes. By considering the drift angle between the north and the bridge axis, the monitored GPS data can be transformed into transverse and longitudinal displacements as shown in Fig. 7. Therefore, transverse and vertical displacements of the girder as well as the transverse and longitudinal displacements of the towers can be obtained.

Traditionally, the monitored displacements can be separated into two components, i.e., the static and dynamic components. The static displacements can be obtained by calculating the $10 \mathrm{~min}$ average values or using trend extraction methods such as autoregressive moving average model (ARMA). The dynamic displacements can then be obtained by subtracting the time-varying averages from the monitored responses. For example, the transverse displacements of the girder monitored by GPS3-01 are shown in Fig. 8 (a). The static displacements are successfully extracted using ARMA and then plotted using red solid line. Because of the electromagnetic interference and shielding on the GPS, a few outliers can be clearly observed in the obtained dynamic displacement as shown in

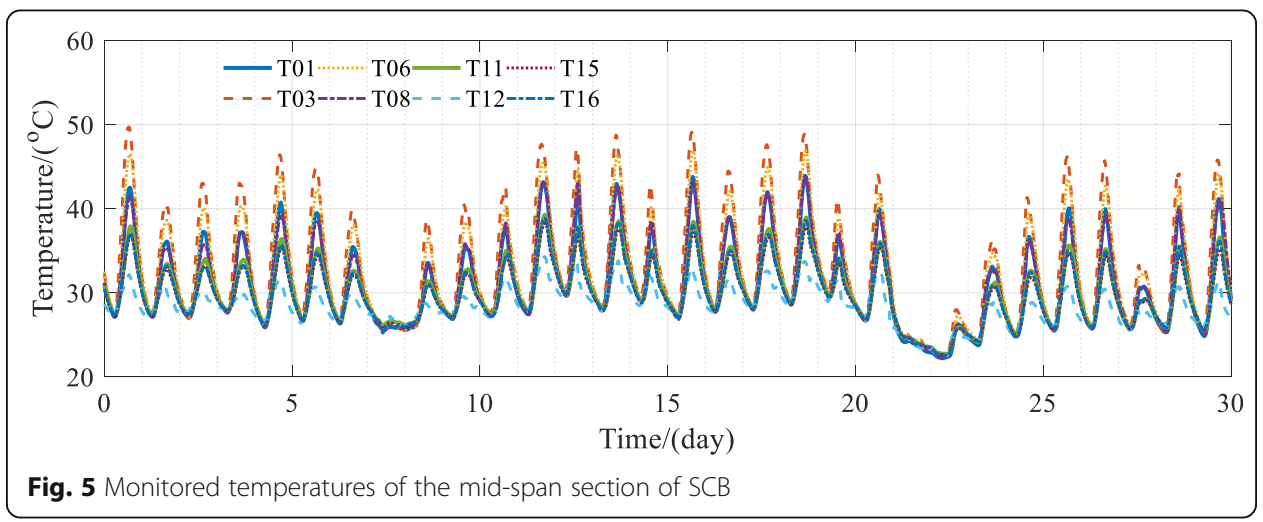




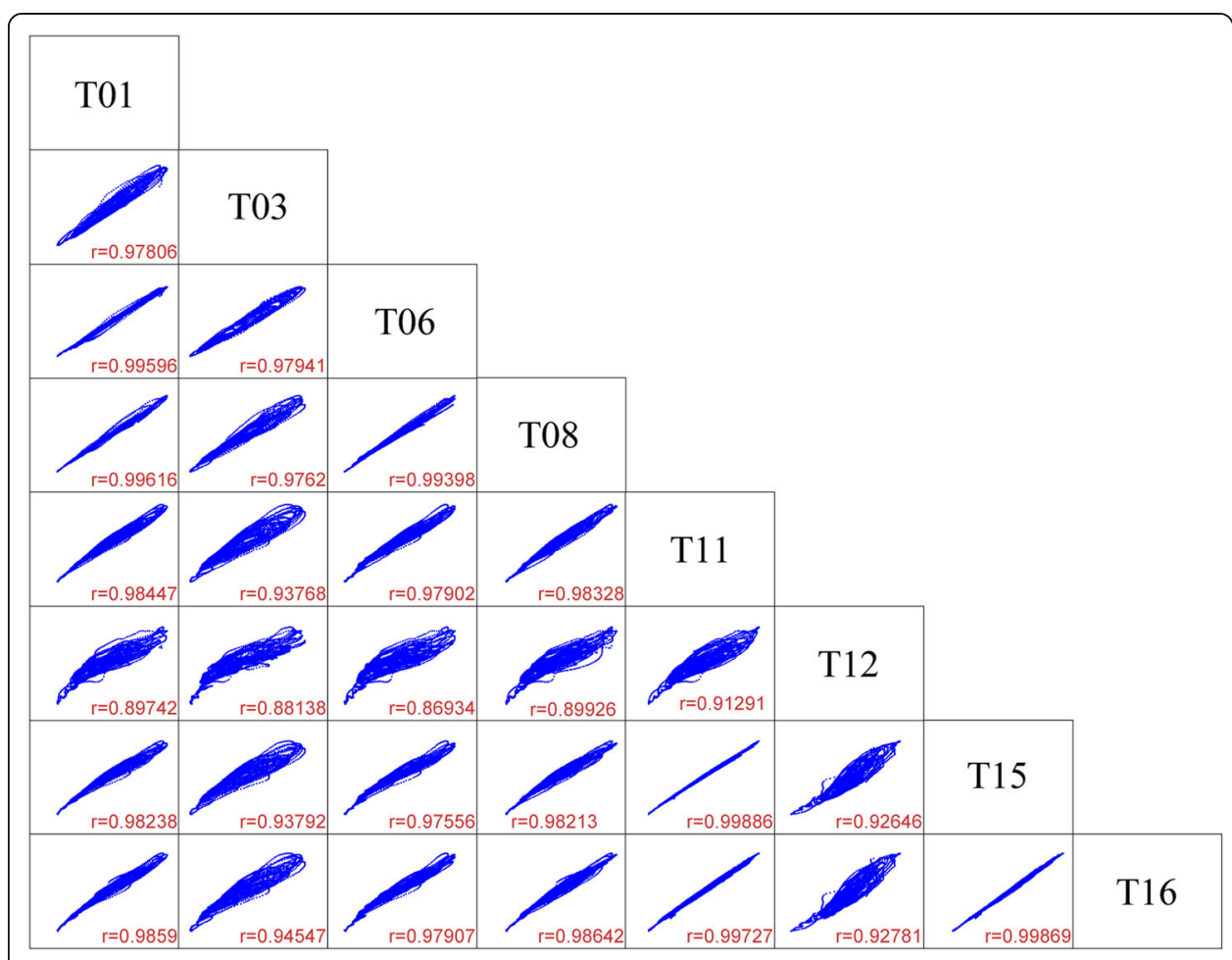

Fig. 6 Relationship between the monitored temperatures in different channels

Fig. 8 (b). The values, more than three scaled median absolute deviations away from the local median over a specified window, are detected as outliers; the detected outliers are then replaced by the local median. The power spectral density (PSD) of the dynamic displacements is then calculated and plotted in Fig. 8 (c). The colored noise with a power spectral density of $1 /|f|^{\alpha}$ over its frequency range can be clearly observed. $f$ represents the frequency, and $\alpha$ is a determined parameter that is larger than 0 . The low-frequency

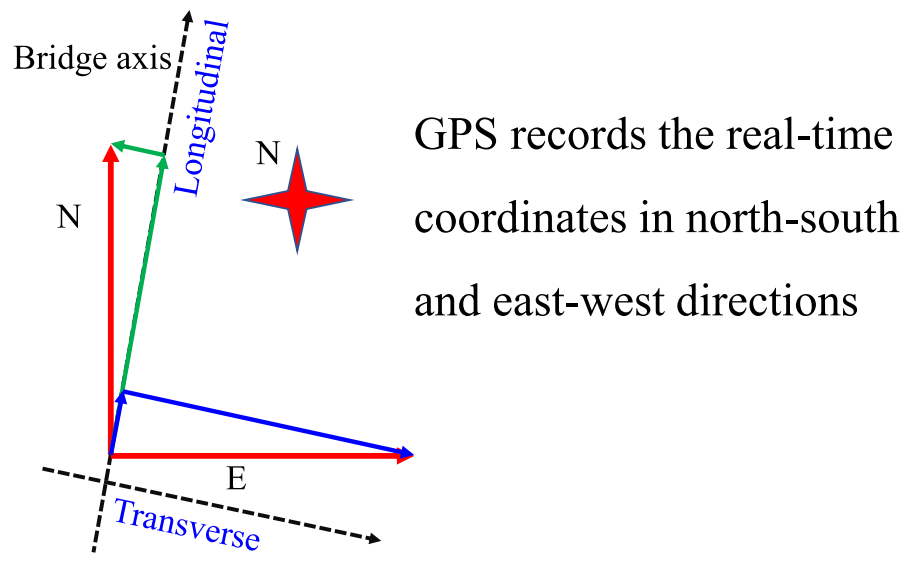

Fig. 7 Decomposing the GPS data into transverse and longitudinal directions 


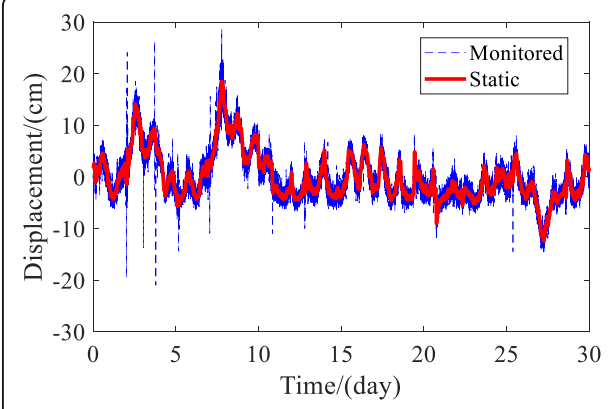

(a) Static displacements

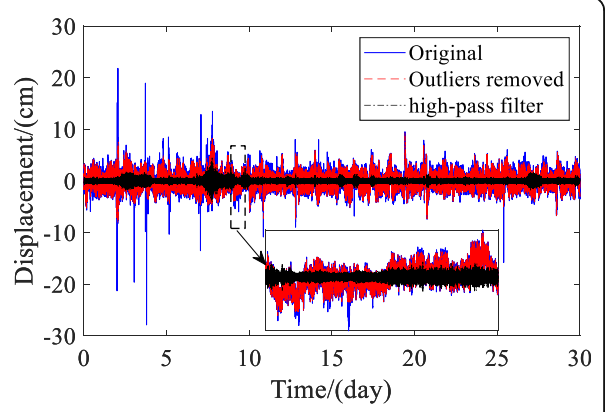

(b) Dynamic displacements

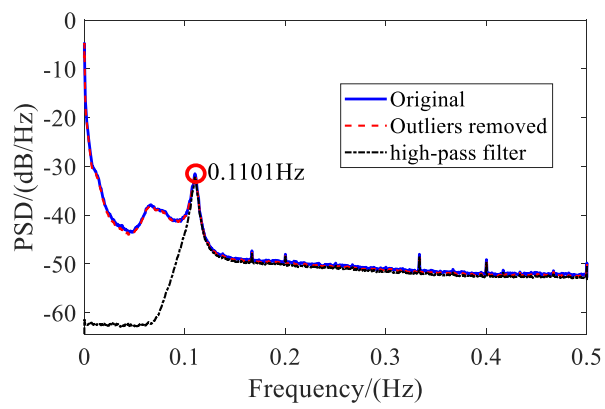

(c) PSD of dynamic displacements

Fig. 8 Static and dynamic transverse displacements monitored by GPS3-01

colored noise may include the system noise and the vibration of the steel pole. The system noise includes the noise induced by system components, i.e., Receiver and Antenna. The Receiver is utilized to calculate a range to all visible satellites. The Antenna is adopted to receive the satellite signals from the Global Navigation Satellite System satellites. The system noise indicates the error derives from calculating the object coordinates according to the signal from Receiver and Antenna. Consequently, a 9th-order digital Butterworth high pass filter is utilized to filter the low-frequency components (smaller than the first natural frequency). The first transverse natural frequency of the main girder is approximately $0.11 \mathrm{~Hz}$ (Wang et al. 2016a). The cutoff frequency of the high pass filter designed using infinite impulse response filter in Matlab is $0.1 \mathrm{~Hz}$ for data sampled at $0.5 \mathrm{~Hz}$. The obtained transverse dynamic displacements are shown in Fig. 8 (b), and the corresponding PSD is shown in Fig. 8 (c). Similarly, the static and dynamic components of all the measured bridge displacements are separated using the above-mentioned rule.

As shown in Fig. 8(b), three obvious peaks of dynamic displacements can be identified after using the high-pass filter; it means the vibration amplitude of the girder increases obviously during typhoons. As shown in Fig. 8(c), an obvious peak at $0.1110 \mathrm{~Hz}$ corresponding to the first transverse natural frequency of the girder can be observed. In addition, some small peaks, whose total energy contribution ratio is rather smaller than $1 \%$, can also be observed. Such the high bending modes of the steel pole may be the potential factor that introduced these small peaks in the GPS responses. To sum up, the transverse dynamic displacements of the girder are mainly controlled by its first mode. 


\section{Analysis of separated static deformations of SCB}

\subsection{Environmental influences on static deformations}

According to the previous sections, the monitored displacements can be separated into the static and dynamic components. For simplicity, the 10-min average of the static displacements is denoted as SD, and the 10-min root mean square (RMS) of the dynamic displacements is denoted as DD. Subscripts $t$ and $v$ represent transverse and vertical directions, respectively. Subscripts $u$ and $d$ represent upstream and downstream sides of the girder, respectively. In addition, subscripts $n$ and $s$ represent north and south towers, respectively. For example, $\mathrm{SD}_{\mathrm{tu}}$ indicates the 10 -min average of the transverse static displacements of the upstream side of the main girder, and $\mathrm{DD}_{\ln }$ represents the 10-min RMS of the longitudinal dynamic displacements of the north tower.

To investigate the relationship between the static displacements and environmental factors including wind speed and temperatures, the scatter matrix, i.e., a pair-wise scatter plot of several variables presented in a matrix format, are applied. The 10-min average wind speed is decomposed into two orthogonal directions, i.e., the cross-axis direction and longitudinal direction. The average wind speed is denoted as F. Subscripts a and 1 represent the cross-axis and longitudinal directions, respectively. To be specific, $F_{p}$ indicates the average wind speed perpendicular to the bridge axis, and $F_{1}$ represents the wind speed parallel to the bridge axis. Temperature is denoted as $T ; T_{m}$ represents the average temperature at the mid-span section of the girder.

Figure 9 exhibits a scatter matrix about relationships between environmental factors and static displacements of the main girder of SCB. The Pearson correlation coefficients between all pairs of variables are calculated. The Pearson correlation coefficient

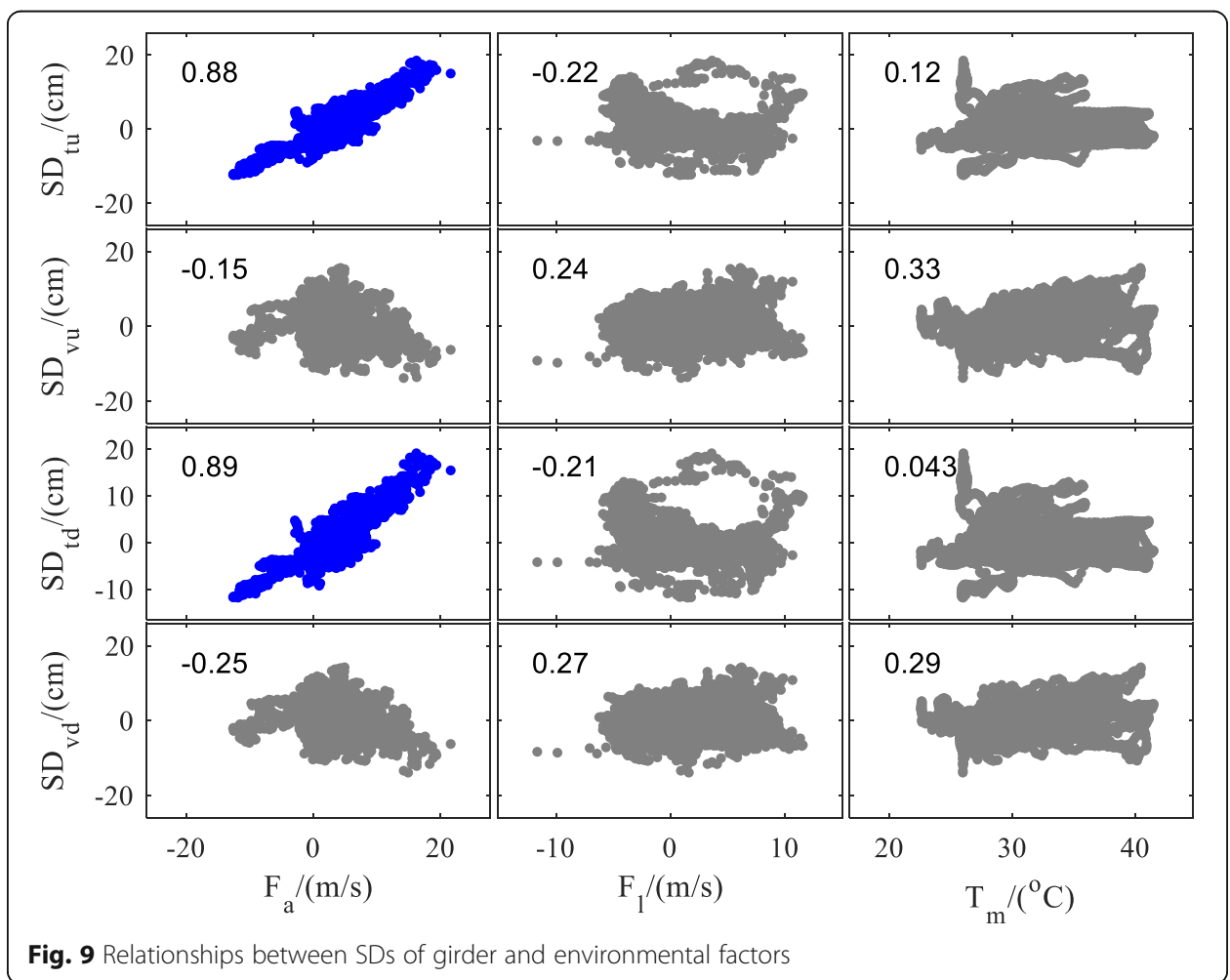

Fig. 9 Relationships between SDs of girder and environmental factors 
is equal to the covariance of two variables divided by the product of their standard deviations (Kenney and Keeping 1962).

As shown in Fig. 9, the correlation coefficient between $\mathrm{SD}_{\text {tu }}$ and $\mathrm{F}_{\mathrm{a}}$ is 0.88 , and that between $\mathrm{SD}_{\mathrm{td}}$ and $\mathrm{F}_{\mathrm{a}}$ is 0.89 . The correlation coefficients are close to 1, indicating the high linear relationship between SD of the girder and cross-axis wind speed. Specifically, the transverse static displacement increases linearly with the increase of cross-axis wind speed.

In addition, the vertical displacements of the girder are slightly correlated with the temperature; the thermal displacements are overwhelmed by those induced by wind and traffic. In both positive and negative wind speed regions, vertical SDs are observed to increase with the increased absolute value of wind speed $F_{a}$. To be specific, the vertical SDs of the main girder would decrease (i.e., the declining of the girder) with the increase of cross-axis wind speed, however, would increase (i.e., the rise of the girder) with the increased average temperature. One should note that traffic is another important factor controlling the bridge displacement, particularly in the vertical direction. However, the traffic data is not available, such that, this study will not focus on that topic. To sum up, the vertical SD is correlated with both the cross-axis wind speed, temperature, and traffic condition, and the transverse SD is mainly correlated with the cross-axis wind speed.

Figure 10 exhibits a scatter matrix about the relationships between the environmental factors and the SDs of towers. As shown in Fig. 10, the correlation coefficients between longitudinal SDs of the north and south towers and $T_{m}$ are 0.70 and -0.64 , respectively. Results indicate that temperature is the dominant load on the longitudinal SDs of the towers. However, the temperature's effects on the north and south towers are

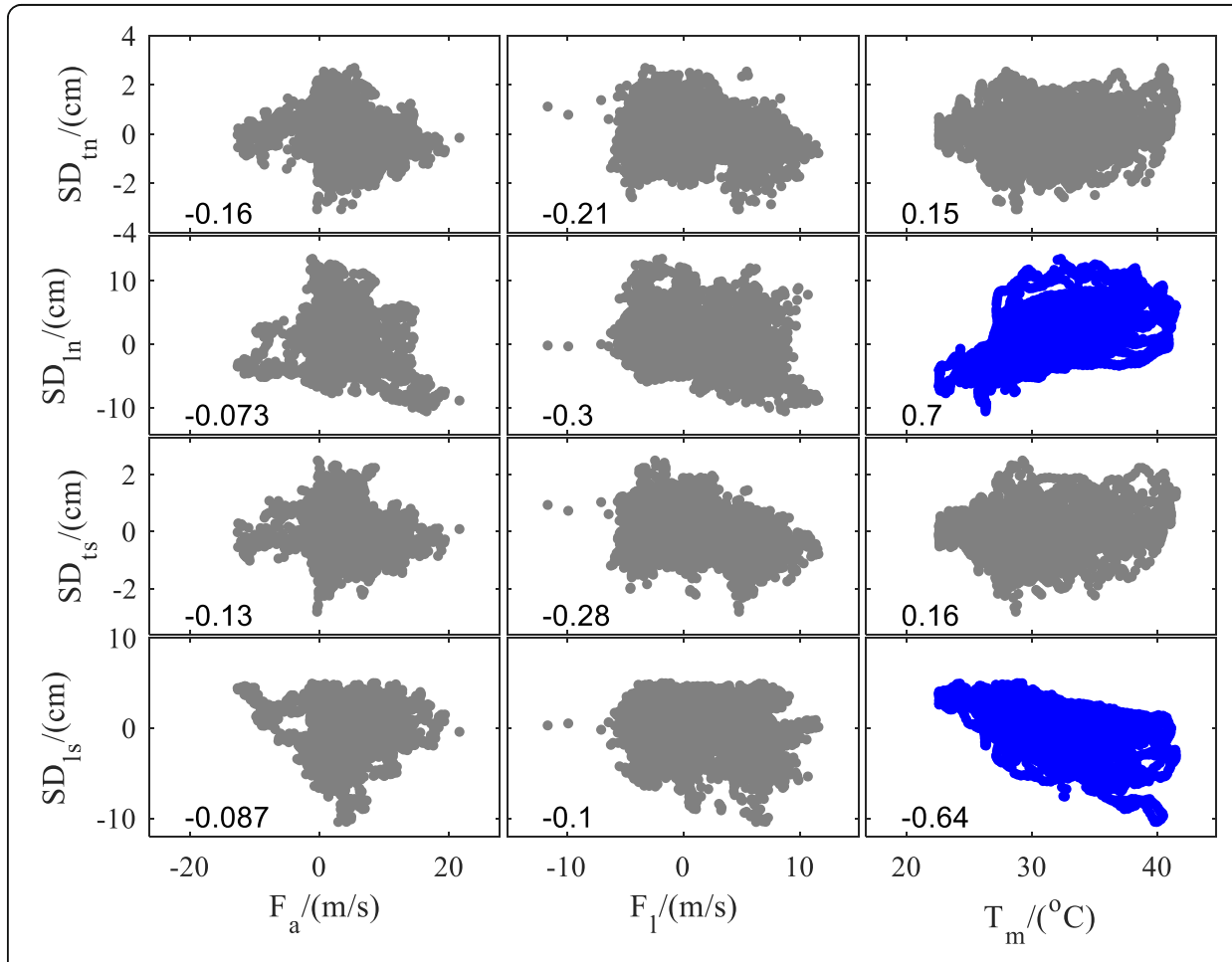

Fig. 10 Relationships between SDs of towers and environmental factors 
different. The temperature is positive correlated (0.7) with the longitudinal SD of the north tower, however, is negative correlated $(-0.64)$ with that of the south tower. It means that the two towers will simultaneously come close or get away with each other when the temperatures changes. On the other hand, the longitudinal SDs of the towers vary between $\pm 10 \mathrm{~cm}$, while their transverse SDs are between $\pm 3 \mathrm{~cm}$. In addition, no obvious correlation between transverse SDs of the towers and environmental factors including wind and temperature can be observed.

\subsection{Correlation between SDs of girder and towers}

In this section, the relationship between the SDs of the girder and towers will be studied according to Fig. 11. The correlation between the vertical SDs of the girder and the longitudinal SDs of the towers is found to be significant. The vertical SDs of the girder, i.e., $\mathrm{SD}_{\mathrm{vu}}$ and $\mathrm{SD}_{\mathrm{vd}}$, are positively correlated with the longitudinal $\mathrm{SD}$ of the north tower $D_{\mathrm{ln}}$, on the contrary, negatively correlated with those of the south tower $D_{\mathrm{ls}}$. This observed phenomenon can be explained that the girder relates to the towers using the stayed cables to provide the vertical stiffness of the system; therefore, the vertical displacements of the girder and the longitudinal displacements of the girder are highly correlated.

As described in Section 3.1, the vertical SDs of the girder and longitudinal SDs of the towers are both correlated with the temperature. Therefore, with the increase/decrease of the temperature, the main girder will go up/down, and the two towers will get away (come close) with each other. The above-mentioned temperature-induced static behavior of the cable-stayed bridge is illustrated using Fig. 12. The above-mentioned

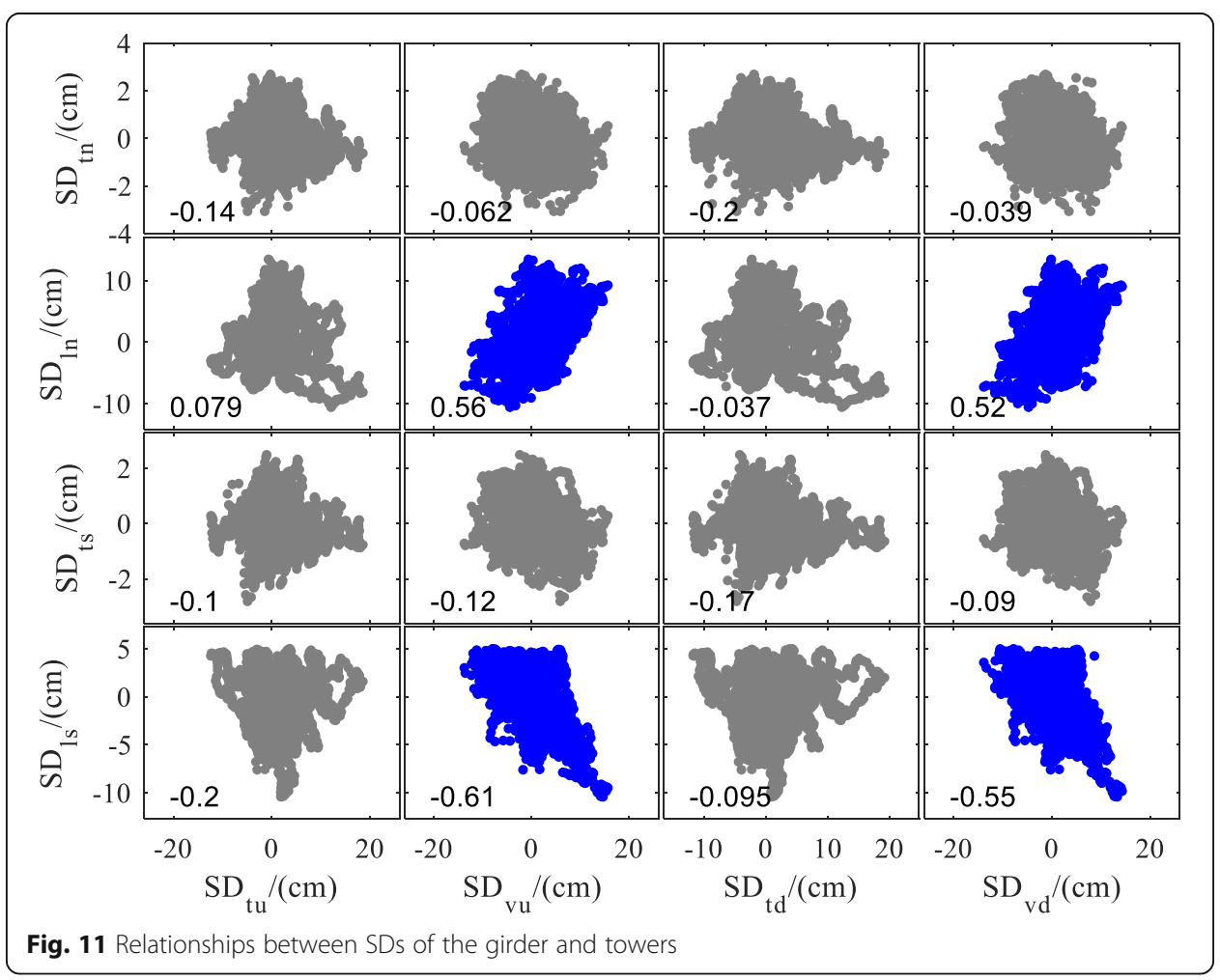




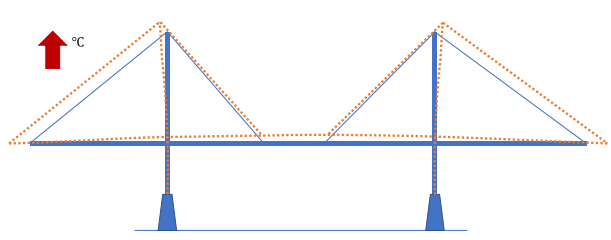

(a) temperature increase

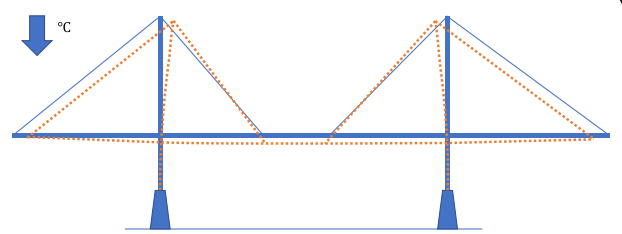

(b) temperature decrease

Fig. 12 Schematics of temperature-induced deformation of the bridge system

temperature-induced deformation behaviors of SCB are similar with those reported by Zhou and Sun (2019a).

\section{Variation of dynamic deformations of SCB with environments}

This section will focus on the variation of dynamic displacements of SCB with respect to the environmental factors including wind speed and temperatures. Instead of directly analyzing the time history of dynamic displacements, the 10-min RMS of dynamic displacements will be studied. DD represents the 10-min RMS of dynamic displacements of the bridge.

The scatter matrix between DDs of the main girder and environmental factors is shown in Fig. 13. The correlation coefficients between DDs and $F_{a}$ are 0.72, 0.63, 0.71, and 0.63 , respectively, indicating a strong correlation between DDs of the main girder and the cross-axis wind speed. DDs keep relatively stable when $F_{a}$ is smaller than $10 \mathrm{~m} /$ s. During that period, the wind-induced girder vibration is relatively low and could be submerged by the device noise and traffic loads. When $F_{a}$ is larger than $10 \mathrm{~m} / \mathrm{s}$, DDs of the girder increase sharply with the increased wind speed. Besides, the correlation

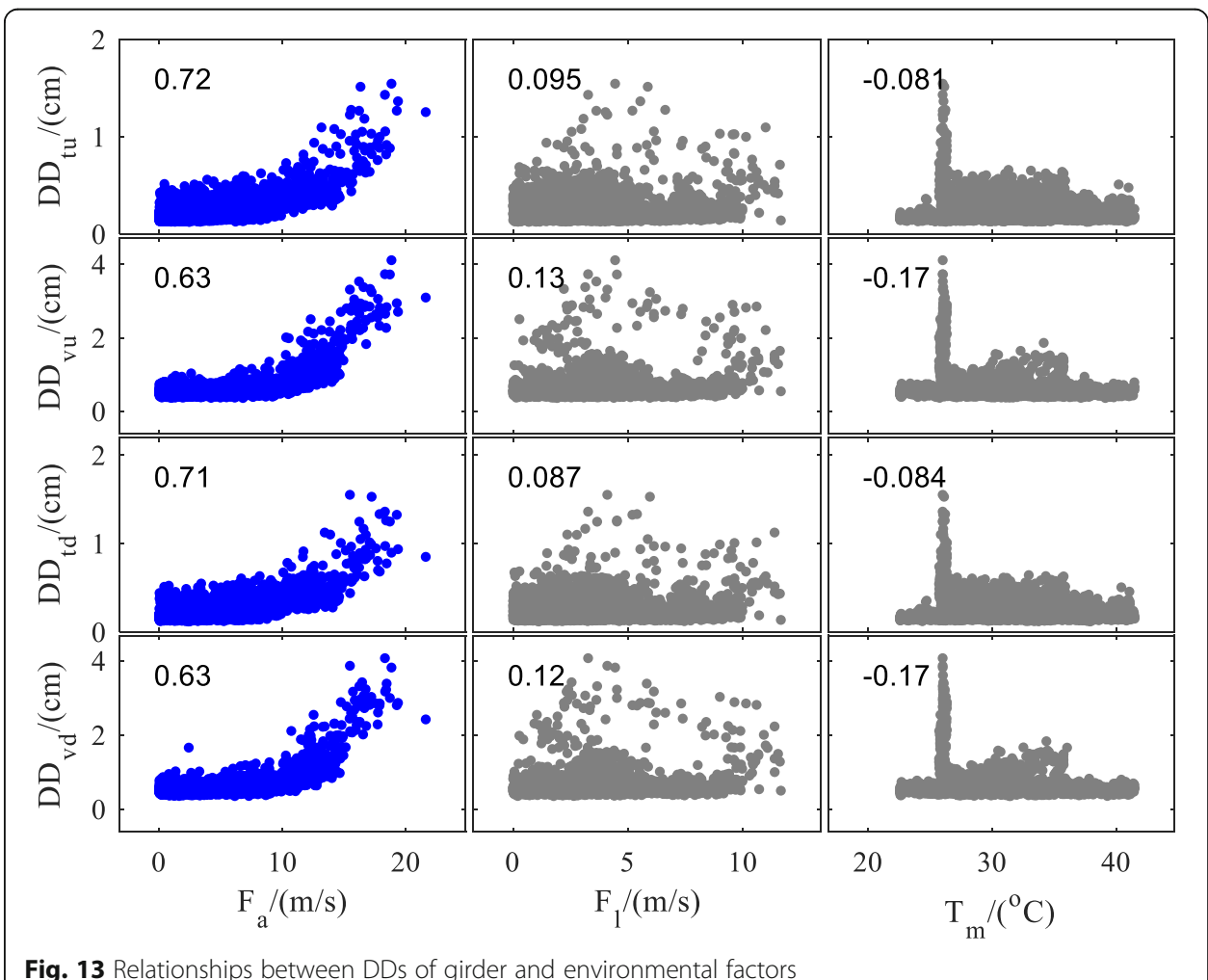

Fig. 13 Relationships between DDs of girder and environmental factors 
between DDs and longitudinal wind speed $F_{1}$ is weak. Similarly, no obvious relationship can be found between DDs and structural temperature. During typhoon Haikui, the environmental temperature is concentrated around $26^{\circ} \mathrm{C}$. The vibration amplitude increased to a high level during that time. Therefore, an obvious peak can be observed in the figure depicting correlation between temperature and vibration amplitude.

The scatter matrix between DDs of the towers and environmental factors is shown in Fig. 14. The transverse DDs of the towers are observed to be weakly correlated with the monitored environmental factors including wind and temperature. It can be explained that that the precision of GPS is not enough; such that, the measured dynamic displacements of the towers in transverse direction are not reliable. As mentioned above, the precision of the GPS is $1 \mathrm{~cm}$, however, the maximum transverse dynamic displacement of the towers is smaller than $1 \mathrm{~cm}$ because of the large transverse stiffness of the towers. Similarly, one can find that the longitudinal dynamic displacements of the towers keep relatively stable when $F_{a}$ is smaller than $10 \mathrm{~m} / \mathrm{s}$. During that period, the longitudinal vibration amplitude of towers is relatively low and could easily be submerged by the device noise. When $F_{a}$ is larger than $10 \mathrm{~m} / \mathrm{s}$, an obvious increasing trend of the longitudinal dynamic displacements of the towers can be identified with the increasing wind speed.

The longitudinal dynamic displacements of the towers are obviously positively correlated with the cross-axis wind speed $F_{a}$. This is similar with the variation trend of the girder displacements with the wind speed as shown in Fig. 13. As shown in Fig. 15, the vertical girder displacements are strongly linearly correlated with the longitudinal displacements of the towers as their correlation coefficients are all around 0.9. The major

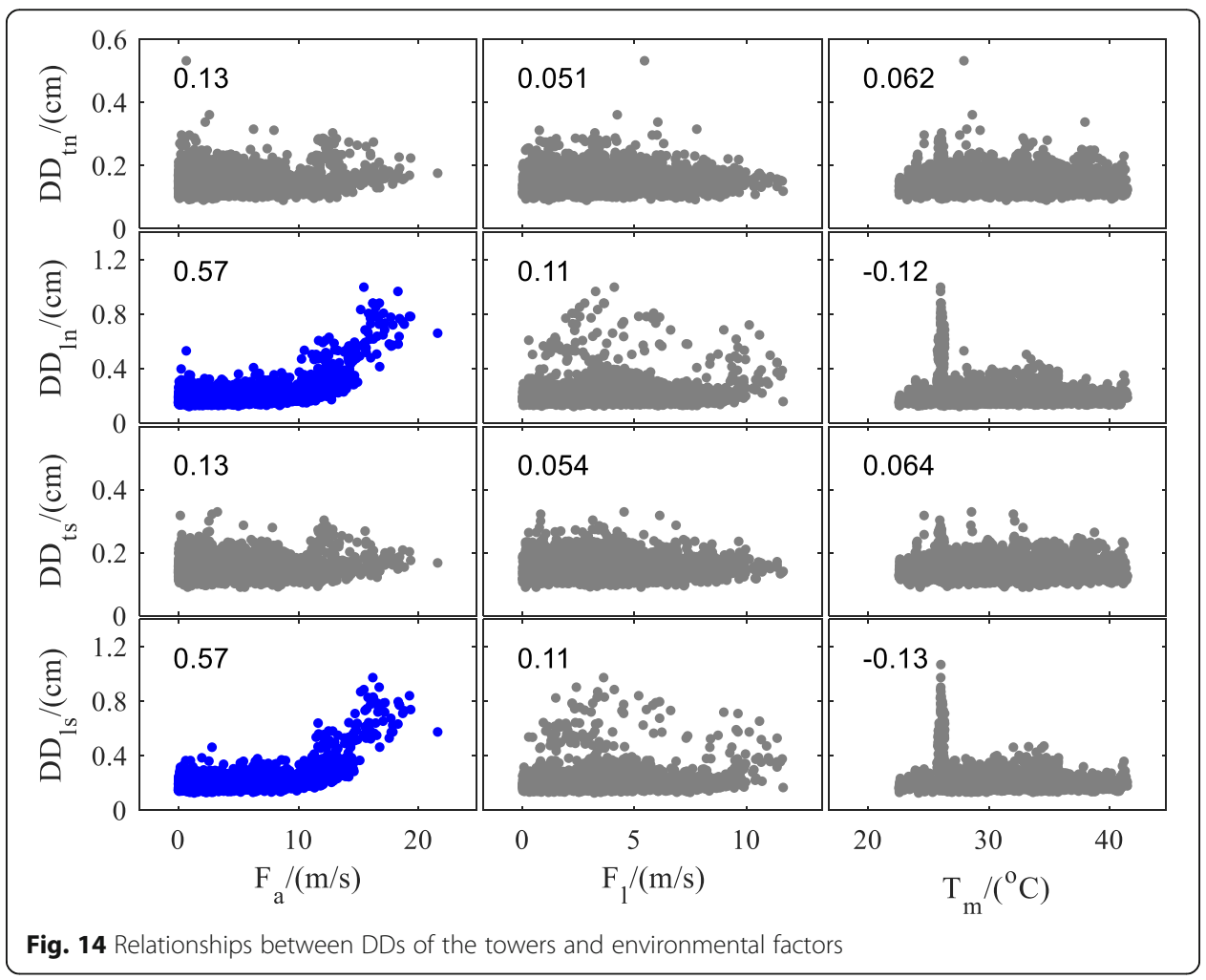



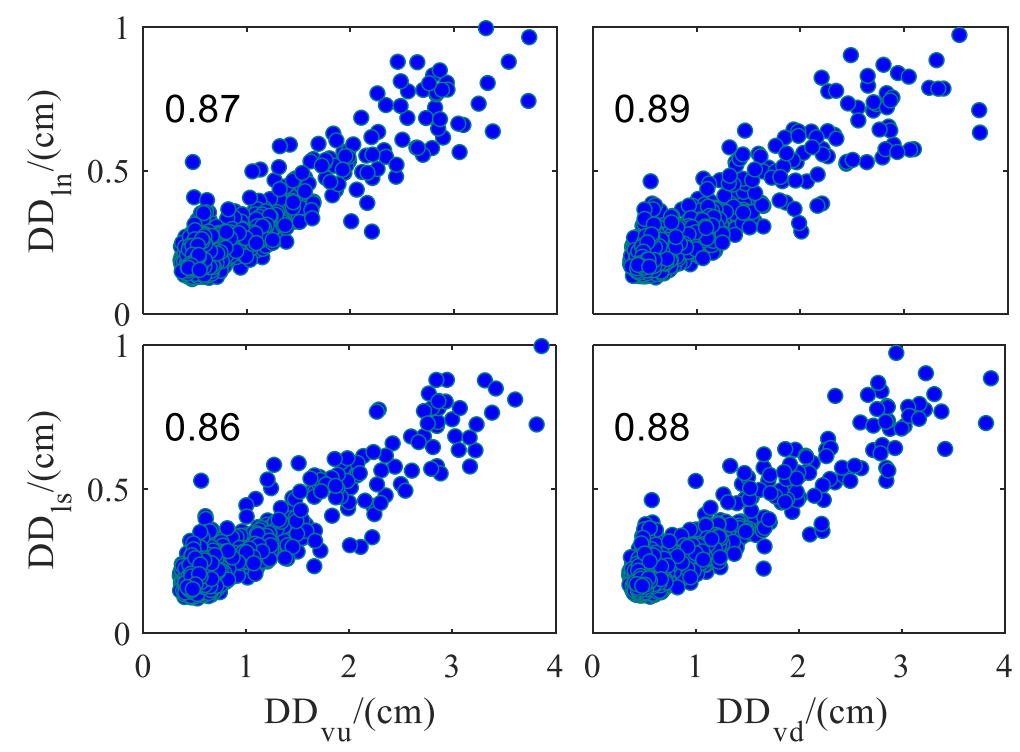

Fig. 15 Relationships between DDs of the girder and towers

reason may be that the stayed cables connect the towers and the main girder and make them work together.

The wind-induced dynamic displacements of the bridge girder are important indicators for safety and serviceability assessment under strong winds or typhoons. Therefore, the data segments whose corresponding corss-axis wind speed is larger than $10 \mathrm{~m} / \mathrm{s}$ are selected to fit the benchmark model following the power law as shown in Eq. (3). In addition, wind-tunnel experiments were carried to obtain the wind-induced dynamic displacements of the girder before SCB was constructed (Xu et al. 2012). The threedimensional geometric parameters of the wind tunnel are respectively $15 \mathrm{~m}$ (width), 2 $\mathrm{m}$ (height), and $14 \mathrm{~m}$ (length). The turbulence intensity of the generated uniform wind was controlled smaller than $1 \%$. Series of cells were adopted to generate turbulent wind. The turbulence intensities at different heights in the wind tunnel are shown in Fig. 16. $U_{r e f}$ indicates the wind speed at the reference location, i.e., the bridge deck.

The experimental results of the aerodynamic elastic model of SCB are also utilized to fit the model in Eq. (3). Therefore, the dynamic displacements with respect to the reduced wind speed based on full-scale measurements and scaled experiments are visualized in Fig. 17.

$$
\hat{\sigma}_{i}=\alpha_{0}\left(U_{r}\right)^{\alpha_{1}}
$$

where $\hat{\sigma}_{i}$ is the predicted RMS of dynamic displacements of the main girder, $\alpha_{0}$ and $\alpha_{1}$ are the parameters to be determined, $U_{r}$ is the reduced wind speed and equals to $F_{a} l$ $\left(f_{c} \mathrm{~B}\right) . f_{c}$ is the first-order natural frequency in the corresponding direction, and $\mathrm{B}$ is the width of the bridge deck, i.e., $41 \mathrm{~m}$. The first-order transverse and vertical natural frequencies are respectively 0.1010 and $0.1841 \mathrm{~Hz}$ (Mao et al. 2019a).

As shown in Fig. 17, the model shown in Eq. (3) can properly describe the variation of dynamic displacements of the bridge girder for the wind tunnel experiments. The full-scale monitored results only cover a small range as illustrated in the red 


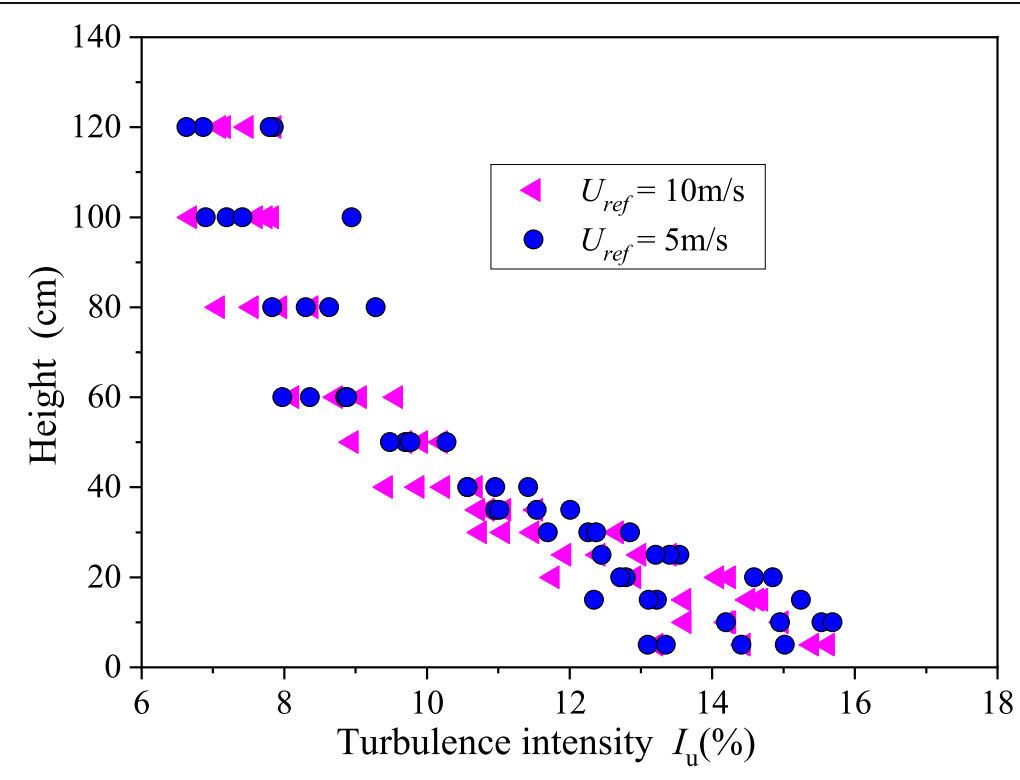

Fig. 16 Turbulence intensities of the turbulent wind in wind tunnel experiments

rectangular box. In the vertical direction, the monitored reduced wind speed is smaller than 3, and that in the transverse direction is smaller than 5. In the monitored windspeed range, the monitoring-based fitted line is relatively close the fitted line based on the turbulent wind tunnel experiments. Specifically, in the vertical direction, the monitoring-based fitted line is a little smaller than the fitted line based on turbulent experiments, while that in the transverse direction can generally match with the fitted line based on turbulent experiments. In addition, in the high wind period, the monitoringbased fitted line is much larger than the that based on turbulent experiments. The available full-scale monitored data samples are limitted and generally concentrated in the small range; this issue may bridge bias into the fitted bechmark model. More field measurements are required, particularly during high wind speed periods, to establish an

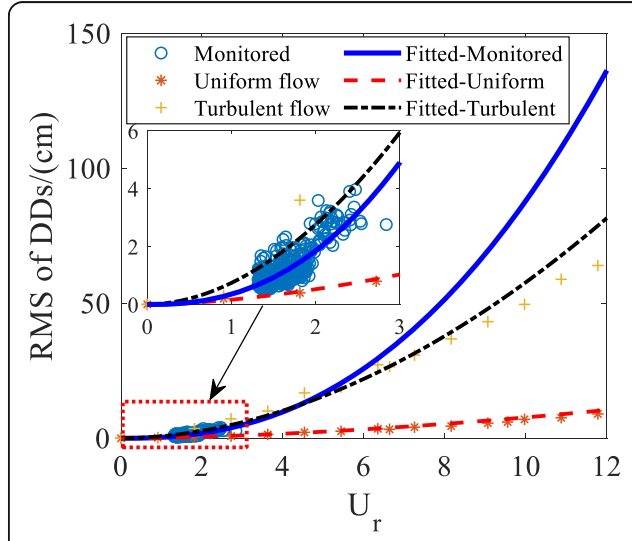

(a) Vertical

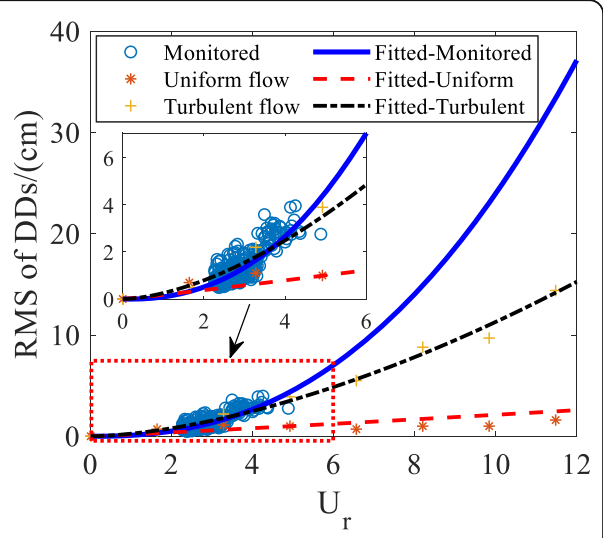

(b) Transverse

Fig. 17 Comparison of the wind-induced dynamic displacements from full-scale measurements and wind tunnel experiments 
accurate wind-induced vibration model that can be utilized for safety and seviceability assessment.

\section{Conclusions}

The SHM system of SCB recorded its structural displacements and in-situ environments during August 2012 when three typhoons occurred. The recorded data was utilized to investigate the variation of the bridge deformations with respect to the structural temperatures and in-situ winds. Conclusions could be summarized as follows.

(1) Some outliers are included in the recorded GPS data. It is necessary to detect and remove these outliers before the subsequent analysis. In addition, the colored lowfrequency noise can be observed in the separated dynamic displacements. A high pass filter can be utilized to eliminate the low-frequency components by setting its cut-off frequency a little smaller than the first-order natural frequency.

(2) The structural temperature is the major factor than controls the static deformation of the girder and towers. With the increase/decrease of the temperature, the main girder will go up/down, and the two towers will get away (come close) with each other. When the structural temperature at the mid-span section varies from $20^{\circ} \mathrm{C}$ to $40^{\circ} \mathrm{C}$, the change of the longitudinal static displacement of the tower is approximately $20 \mathrm{~cm}$.

(3) The dynamic deformations of the girder are generally controlled by the in-situ wind speed; however, the influence of structural temperature is limited. The vertical girder displacements are strongly correlated with the longitudinal deformation of the towers as their correlation coefficients are all around 0.9. The major reason may be that the stayed cables connect the towers and the main girder and make them work together.

The available full-scale monitored data samples are generally concentrated in a small range; this issue may introduce bias into our understanding of the wind-induced bridge deformation. More field measurements, particularly during extremely strong wind periods, will be carried out to grap wind-induced bridge behavior in the future.

\section{Abbreviations}

SHM: Structural health monitoring; GPS: Global positioning system; SCB: Sutong cable-stayed bridge; ARMA: Autoregressive moving average model; PSD: Power spectral density; SD: Static displacements; DD: Dynamic displacements; RMS: Root mean square

\section{Acknowledgements}

The comments and suggestions on analyzing the GPS data from Prof. Billie F. Spencer Jr. and Dr. Yuguang Fu of the University of Illinois at Urbana-Champaign are acknowledged. The comments and suggestions on wind-induced vibration from Mr. Zidong Xu of Southeast University are also acknowledged. 


\section{Availability of data and materials}

The data that support the findings of this study are available from JSTI Group but restrictions apply to the availability of these data, which were used under license for the current study, and so are not publicly available. Data are however available from the authors upon reasonable request and with permission of JSTI Group.

\section{Competing interests}

The authors declare that they have no competing interests.

\section{Author details}

${ }^{1}$ Key Laboratory of C\&PC Structures of Ministry of Education, Southeast University, Nanjing 201189, China. ${ }^{2}$ State Key Laboratory of Safety and Health for In-Service Long Span Bridges, Nanjing 211112, China. ${ }^{3}$ Department of Civil and Environmental Engineering, University of Illinois at Urbana-Champaign, Urbana 61801, USA.

Received: 20 March 2020 Accepted: 6 July 2020

Published online: 18 August 2020

\section{References}

Ashkenazi, V., \& Roberts, G. (1997). Experimental monitoring of the Humber bridge using Gps. Proceedings of the Institution of Civil Engineers-Civil Engineering

Billah KY, Scanlan RH (1991) Resonance, Tacoma narrows bridge failure, and undergraduate physics textbooks. Am J Phys 59(2):118-124

CMA. (2012). Available from Chinese Typhoon Online, from China Meteorological Administration (CMA) http://www.typhoon. org.cn/

Feng D, Feng MQ (2016) Vision-based multipoint displacement measurement for structural health monitoring. Struct Control Health Monit 23(5):876-890

Fujino Y, Siringoringo DM, Abe M (2016) Japan's experience on long-span bridges monitoring. Struct Monit Maintenance 3(3):233-257

Fujino Y, Yoshida Y (2002) Wind-induced vibration and control of trans-Tokyo Bay crossing bridge. J Struct Eng 128(8): 1012-1025

Gomez F, Park JW, Spencer BF Jr (2018) Reference-free structural dynamic displacement estimation method. Struct Control Health Monit 25(8):e2209

Hao J, Wu T (2018) Downburst-induced transient response of a long-span bridge: a Cfd-Csd-based hybrid approach. J Wind Eng Ind Aerodyn 179:273-286

Huang G, Chen X (2009) Wavelets-based estimation of multivariate evolutionary spectra and its application to nonstationary downburst winds. Eng Struct 31(4):976-989

Hwang YC, Kim S, Kim HK (2019) Cause investigation of high-mode vortex-induced vibration in a long-span suspension bridge. Struct Infrastructure Eng 16(1):84-93

Im SB, Hurlebaus S, Kang YJ (2011) Summary review of Gps Technology for Structural Health Monitoring. J Struct Eng 139(10): 1653-1664

Jo H, Sim SH, Tatkowski A, Spencer B Jr, Nelson ME (2013) Feasibility of displacement monitoring using low-cost Gps receivers. Struct Control Health Monit 20(9):1240-1254

Kenney JF, Keeping E (1962) Linear regression and correlation. Math Stat 1:252-285

$\mathrm{Ko} \mathrm{J,} \mathrm{Ni} \mathrm{Y} \mathrm{(2005)} \mathrm{Technology} \mathrm{developments} \mathrm{in} \mathrm{structural} \mathrm{health} \mathrm{monitoring} \mathrm{of} \mathrm{large-scale} \mathrm{bridges.} \mathrm{Eng} \mathrm{Struct} \mathrm{27(12):}$ $1715-1725$

Mao JX, Wang H, Fu YG, Spencer BF (2019a) Automated modal identification using principal component and cluster analysis: application to a long-span cable-stayed bridge. Struct Control Health Monit 26(10):e2430

Mao JX, Wang H, Li J (2019b) Fatigue reliability assessment of a long-span cable-stayed bridge based on one-year monitoring strain data. J Bridg Eng 24(1):05018015

Miyata T, Yamada H, Katsuchi H, Kitagawa M (2002) Full-scale measurement of Akashi-Kaikyo bridge during typhoon. J Wind Eng Ind Aerodyn 90(12-15):1517-1527

Mufti AA (2002) Structural health monitoring of innovative Canadian civil engineering structures. Struct Health Monit 1(1):89-103

Nassif HH, Gindy M, Davis J (2005) Comparison of laser Doppler Vibrometer with contact sensors for monitoring bridge deflection and vibration. Ndt E Int 38(3):213-218

Ou JP, Li H (2010) Structural health monitoring in mainland China: review and future trends. Struct Health Monit 9(3):219-231

Spencer BF, Ruiz-Sandoval ME, Kurata N (2004) Smart sensing technology: opportunities and challenges. Struct Control Health Monit 11(4):349-368

Sun Z, Zou Z, Zhang Y (2017) Utilization of structural health monitoring in long-span bridges: case studies. Struct Control Health Monit 24(10):e1979

Wang H, Mao JX, Huang JH, Li A (2016a) Modal identification of Sutong cable-stayed bridge during typhoon Haikui using wavelet transform method. J Perform Constr Facil 30(5):04016001

Wang H, Tao T, Li A, Zhang Y (2016b) Structural health monitoring system for Sutong cable-stayed bridge. Smart Struct Syst 18(2):317-334

Xing CX, Wang H, Li AQ, Xu Y (2014) Study on wind-induced vibration control of a long-span cable-stayed bridge using Tmd-type counterweight. J Bridg Eng 19(1):141-148

Xu FY, Chen XZ, Cai CS, Chen AR (2012) Determination of 18 flutter derivatives of bridge decks by an improved stochastic search algorithm. J Bridg Eng 17(4):576-588

Xu Y, Chen B, Ng C, Wong K, Chan W (2010) Monitoring temperature effect on a long suspension bridge. Struct Contro Health Monit 17(6):632-653

Xu, Y. L., \& Chan, W. S. (2009). Wind and Structural Monitoring of Long Span Cable-Supported Bridges with Gps. The 7th AsiaPacific conference on wind engineering (APCWE09) 
Xu YL, Chen J (2004) Characterizing nonstationary wind speed using empirical mode decomposition. J Struct Eng 130(6):912-920

Yi TH, Li HN, Gu M (2013a) Experimental assessment of high-rate Gps receivers for deformation monitoring of bridge. Measurement 46(1):420-432

Yi TH, Li HN, Gu M (2013b) Recent research and applications of Gps-based monitoring Technology for High-Rise Structures. Struct Control Health Monit 20(5):649-670

Zhang W, Cai C, Pan F, Zhang Y (2014) Fatigue life estimation of existing bridges under vehicle and non-stationary hurricane wind. J Wind Eng Ind Aerodyn 133:135-145

Zhang Y, Wang H, Mao J, Wang F, Hu S, Zhao X (2018) Monitoring-based assessment of the construction influence of Benoto pile on adjacent high-speed railway bridge: case study. J Perform Constr Facil 33(1):04018106

Zhou GD, Yi TH, Chen B, Chen X (2018) Modeling deformation induced by thermal loading using long-term bridge monitoring data. J Perform Constr Facil 32(3):04018011

Zhou Y, Sun LM (2019a) A comprehensive study of the thermal response of a long-span cable-stayed bridge: from monitoring phenomena to underlying mechanisms. Mech Syst Signal Process 124:330-348

Zhou Y, Sun LM (2019b) Insights into temperature effects on structural deformation of a cable-stayed bridge based on structural health monitoring. Struct Health Monit 18(3):778-791

Zhu J, Zhang W (2016) Numerical simulation of wind and wave fields for coastal slender bridges. J Bridg Eng 22(3):04016125

Zhu LD, Li L, Xu YL, Zhu Q (2012) Wind tunnel investigations of aerodynamic coefficients of road vehicles on bridge deck. J Fluids Struct 30:35-50

\section{Publisher's Note}

Springer Nature remains neutral with regard to jurisdictional claims in published maps and institutional affiliations.

Submit your manuscript to a SpringerOpen ${ }^{\odot}$ journal and benefit from:

- Convenient online submission

- Rigorous peer review

Open access: articles freely available online

- High visibility within the field

- Retaining the copyright to your article

Submit your next manuscript at $>$ springeropen.com 